Ankara Üniversitesi Türk İnkılâp Tarihi Ensitüsü Atatürk Yolu Dergisi

S 24, Kasim 1999-2003 s. 469-474

\title{
Milli Mücadele'de Balıkesir
}

Prof. Dr. Zeki Arıkan*

Mücteba İlgürel, Milli Mücadele’de Balıkesir Kongreleri, Atatürk Araştırma Merkezi, İstanbul, 1999, X + 353s.

Uzun yıllardan beri Balıkesir ve çevresinin Milli Mücadele sürecindeki yerini belirlemek için büyük bir çaba gösteren Prof.Dr. Mücteba İlgürel'in yukarıdaki başlık altında hazırladığı bu çalışma, önemli bir boşluğu doldurmaktadır. Yazarın bu yurt köşesinde doğmuş olması, dedesinin Kuvayı Milliye hareketi içinde yer almış bulunması herhalde böyle bir çalışmada belirleyici bir rol oynamıştır. Böylece bu eseri sayın İlgürel'in memleketine duyduğu sevginin, ecdadına ve bütün Kuva-yı Milliyecilere beslediği saygının bir ifadesi olarak değerlendirmek gerekir. Öncelikle yazarın çok geniş bir kaynakçadan yola çıktığını özellikle belirtmeliyiz. Başbakanlık Osmanlı Arşivi'nin (İstanbul), Milli Mücadelenin başlangıcı açısından oldukça zengin malzemeyi kapsadığını bu çalışma yeterince ortaya koymaktadır. Türk İnkılap Tarihi Enstitüsü Arşivi'nin de bu bağlamda önemi büyüktür. Prof. İlgürel, bu arşiv belgelerinin dışında yerel gazete ve dergilerdeki yazıları anıları da sağlıklı bir biçimde değerlendirme yoluna gitmiştir. Bütün bunların yanında diğer kaynaklar ve incelemeler de titizlikle taranmış ve kullanılmıştır.

Batı Anadolu'da toplanan kongrelere ilişkin belge ve tutanaklar şu ya da bu nedenle yok olmuş fakat Balıkesir Kongrelerinden günümüze epeyce malzeme kalmıştır. Hareketin içinde yer alan Hacim Muhittin'in belgesel nitelikteki anılarının dışında I., II. ve IV. Balıkesir Kongrelerinin kararları günümüze ulaşmıştır. Ayrıca Redd-i İşgal Heyeti Teşkilat Encümeni Karar Defteri de bize kadar gelmiştir. Bütün bu belgeler Balıkesir Redd-i İlhak Müzesinde bulunmaktadır ${ }^{1}$. Bunların bıraktı̆̆ 1 boşlukları ise İzmir'e Doğru gazetesindeki yazı ve haberler tamamlamaktadır.

Yazar, oldukça mütevazi davranarak eserin başlı̆̆ını "Milli Mücadele'de Balıkesir Kongreleri” olarak adlandırmıştır. Oysa bu başlık, kitabın içeriğini

\footnotetext{
•Ege Üniversitesi

'Fuat Özer, Milli Mücadele'de Balıkesir, İ.Ü. Atatürk İlkeleri ve İnkılap Tarihi Enstitüsü Doktora Tezi, 1998.
} 
tam olarak yansıtmamaktadır. Çünkü eserde yalnızca Balıkesir Kongreleri işlenmemekte, tam tersine Mütareke'nin imzalanmasından Balıkesir'in işgaline kadar geçen zaman dilimi içinde Batı Anadolu'daki gelişmeler ele alınıp işlenmekte, değerlendirilmekte ve yorumlanmaktadır. Böylece bu çalışmanın yalnız Balıkesir'de toplanan beş kongreye değil, aynı zamanda Milli Mücadele tarihine de önemli bir ışı tuttuğunu rahatlıkla söyleyebiliriz.

İzmir'in işgali (15 Mayıs 1919) Balıkesir'in önemini kat kat arttırmış ve kısa sürede bu kent, Kuva-yı Milliye'nin karargâhı haline gelmişti. Ülkenin içinde bulunduğu tehlike karşısında halkı bilinçlendirmek ve yurt sevgisini güçlendirmek için Ses gazetesi yayına girmişti. Ne yazık ki bu gazete uzun ömürlü olmamış, İzmir'in işgalinden iki ay önce (13 Mart 1919) kapatılmıştır. Yine Balıkesir'de oluşan "Redd-i İlhak Cemiyeti" çabucak büyümüş ve Mustafa Kemal Paşa ile iletişim kurarak Milli Mücadele'nin başarıya ulaşmasında önemli bir rol oynamıştır. Balıkesir, işgalden sonra İzmir'den kaçıp buraya gelen aydınların önemli bir merkezi konumuna gelmişti. Kuva-yı Milliye'nin mürevvic-i efkârı işlevini gören İzmir'e Doğru gazetesinin çıkışını da bu bağlamda değerlendirmek gerekir. Gazete, adres olarak Balıkesir'de Kuva-yı Milliye Karargâhı'nı gösterdiği gibi hedef olarak da İzmir'e ulaşmaya çalışıyordu. Gazetenin çok güç koşullar altında İzmir'in çocukları tarafından gizlice burada satılması, işgal altındaki halka yaşama gücü veriyor ve umut aşılıyordu. İzmir'e Doğru'nun yayınlanmasında Mustafa Necati, Vasıf ve Esat (Çınar) kardeşlerin çok büyük rol oynadıklarına şüphe yoktur. Vasıf'ın bu gazetedeki coşku dolu yazıları ${ }^{2}$, Necati'nin Kurtuluş Savaşını bir bütün olarak ele alan makaleleri, o günlerin ruhsal durumunu da yansıtan çok önemli belgeleri olarak görülmektedir. Bu gazetede yer alan haber ve makalelerin İlgürel'in çalışmasında çok geniş ölçüde işlendiğini özellikle vurgulamak gerekir.

Milli Mücadelede Balıkesir'de toplanan beş kongrenin söz konusu eserde oldukça önemli bir yer tuttuğuna şüphe yoktur. Ancak öncelikle şu noktayı belirtelim $\mathrm{ki}$

Milli Mücadele döneminde Erzurum ve Sivas kongrelerinin dişında toplanan diğer kongreleri topluca değerlendiren Prof. Şerafettin Turan, "Kongre" sözcüğünün kullanımındaki belirsizliği ilk dile getiren araştırıcıların başında gelmektedir. Sözcük bu dönemde çok sık kullanılmış hemen her toplantı, kolayca kongre olarak adlandırılmıştır. Kimi zaman birkaç kişinin bir araya gelip bir toplantı yapması da rahatlıkla "Kongre" kapsamına giriyordu. Hacim Muhittin Çarıklı'nın ve İbrahim Tahtaklıç'ın anılarının yayınlanması ve Kurtuluş Savaşı sırasında toplanan diğer kongreler üzerindeki çalışmalar, kongreler konusunu daha da güncelleştirmiştir. Sorun, bir "sivil direniş hareketi" olarak algılandığı gibi,

${ }^{2}$ Tülay Alim Baran, Vasıf Çınar ve İzmir'e Doğru Gazetesi Yazıları, Arma, İstanbul, 2001 . 
yerel bir iktidar bağlamında da değerlendirilmektedir. Nitekim Bülent Tanör. kongreleri farklı bir açıdan değerlendirerek yepyeni bir kavramla konuya yaklaşmıştır. Tanör, bir yandan Yunan işgalinin yayılması diğer yandan da İstanbul hükümetinin görevini yapamaz duruma gelmesi üzerine toplanan kongrelerin bu boşluğu doldurduğundan hareketle bunları, yukarıda değinildiği gibi, "yerel kongre iktidarı" olarak değerlendirmiștir. Daha doğrusu bu kongrelerin vergi salması, asker toplaması gibi devlete ait işlevleri yerine getirmeleri onlarm "iktidar" 1 temsil eder bir konuma gelmelerine ortam hazırlamıştır. Nitekim İlgürel de Balıkesir'de toplanan kongrelerin demokratik yapısına işaret etmektedir. Birinci Okuma Yurdu toplantısına (16 Mayıs 1919) geniș bir halk kitlesi katılmıș ve oluşan meclis, halkın oyu ile işbaşına gelmiştir (s. 68-69). Böylece bölgede vatanın kurtuluşu için ve Erzurum'da toplanacak olan kongreyle işbirliğine girişecek olan "Kuva-yı Milliye" ortaya çıkmıştır. Bu kongrelerin asker toplamaya karar vermesi (s. 79), vergi ihdası (s. 94) gibi eylemleri de onların bölgesel işlevlerini ortaya koymaktadır. Balıkesir'de Kuva-yı Milliye hareketi içinde önemli görevler üstlenen Hayrettin Karan bu yeni yapılanmanın yani Kuvay1 Milliyenin bir "Hükümet-i Muvakkate" olduğuna dikkati çekmektedir (s. 260). Tarık Zafer Tunaya ${ }^{3}$ da bu yeni yapılanma konusunda şu değerlendirmeyi yapmıştır: "Filhakika devletin ne olacağı düşüncesi sadece siyasi partilere değil, "Heyet", "Cemiyet" gibi değişik isimler alan teşekküllere de vücut vermiştir." Yakın zamanda, Uşak Heyet-i Merkeziyesinden yazılan yazıları içeren bir defteri yayına hazırlayan İlhan Tekeli ve Selim İlkin'e göre: hareketin temelinde "gücünï halktan alan, meşruiyetini halka dayanmakta bulan bir örgütlenme" yatmaktadır. Sözün kısası Mütareke'den Sivas Kongresine, başka bir deyimle TBMM'nin açılıp ülkenin yazgısına el koyuncaya kadar Kuva-yı Milliye, Batı Anadolu'da düşman ilerleyişini durdurmaya çalışmak ve yönetim boşluğunu doldurmak gibi çok büyük bir işlevi yerine getirmiş ve bunu yaparken gücünü halka dayanan Kongrelerden almıştır.

Prof. İlgürel, yukarıda değindiğimiz eserinin ana eksenini oluşturan Balıkesir Kongrelerini yetkiyle ele almış ve incelemiştir. Her kongre üzerinde teker teker durulmuş, ötedenberi süregelen kimi yanlışlıklar da düzeltilmiştir. Yine bu bağlamda Kongrelerin aldıkları kararlar ve bu kararların uygulanmalarındaki güçlükler de ele alınıp, tartışılmıştır. Üzerinde durulan ana sorunlarından biri de Balıkesir kongrelerinin Erzurum, Sivas kongreleri ve İstanbul hükümetleri ile olan ilişkilerinin geniş ölçüde araştırılmasıdır. Bütün bunların söz konusu eserde ayrıntılı olarak dile getirildiğini özellikle belirtmek gerekir. Kısaca özetlemek gerekirse:

Alacamescit toplantısında oluşturulan Redd-i İlhak Merkez Heyeti reisi Vehbi Bey'in vergi ihdası konusunda üyelerle arası açılıp istifaya karar vermesi üzerine bu görev o sırada Balıkesir'de bulunan Hacim Muhittin'e

\footnotetext{
${ }^{3}$ Türkiye'de Siyasi Partiler, İstanbul, 1952, 403.
} 
önerildi. Hacim Muhittin bu öneriyi, İstanbul'da toplanacak meclis için aday olmamak koşuluyla kabul etti.

Birinci Balıkesir Kongresi 28 Haziran-12 Temmuz (1919) tarihleri arasında toplandı. Bu kongre girişimi Kâzım Özalp tarafından desteklendi ve onun verdiği bilgilere göre, kongreye Balıkesir dışında Ayvalık, Soma ve Akhisar'dan temsilciler de katıldı. Kongrenin almış olduğu en önemli karar, Yunan kuvvetleriyle savaşmak üzere daha düzenli birliklerin oluşturulması için 318 ilâ 319 (1902-1903) doğumlulara kadar olan kişilerin askere çağrılmasıdır. Altı çizilmesi gereken diğer önemli bir olay da 8-9 Temmuz 1335 (1919)'te Mustafa Kemal Paşa'nın askerlikten ayrıldığını ulusla birlikte mücadeleyi sürdüreceğini belirten telgrafının Balıkesir'e ulaşmasıdır.

Çok geçmeden 26-30 Temmuz (1919) günleri arasında yeni bir kongre topland1 (s. 101-122). Bu kongrede alınan kararlarla Amasya Genelgesinde belirlenen düşüncelerle, Erzurum Kongresinde alınan kararların, Balıkesir Kongresinde farklı bir anlatımla da olsa dile getirilmiş olmasıdır. İkinci Balıkesir Kongresinde alınan kararların en önemlileri, 3. ve 4 . maddede kısaca fakat kesin bir dille ifade edilmişti.

"Teşekkül eden kongremiz... teşkilat-ı muntazama dahilinde Yunanlıları Anadolu'dan tard etmeğe azmetmiştir" ve "kongrenin maksat ve gayesi istihlas-l vatandır" maddeleri dikkati çekmektedir. Prof. "erafettin Turan ${ }^{4}$ bu yöresel kongrenin Milli Kongre olarak nitelendirilmesinin anlamını özellikle vurgulamaktadır. Üstelik alınan kararların Erzurum Kongresi ölçüsünde değilse bile, bölgesellikten çıkıp ulusal bir niteliğe dönüşmesi de üzerinde durulması gereken bir konudur. Balıkesir'de sürdürülen bu çabalar, İstanbul hükümetini epeyce tedirgin etmiş ve bu yüzden Anzavur'un Kuva-yı Milliye'nin başına musallat edilmesi bu ortamda gündeme gelmişti.

$\mathrm{Bu}$ arada 6-9 Ağustos (1919) günlerinde Birinci Nazilli Kongresi yapıldığı gibi, ikinci Balıkesir Kongresi'nin kararlarını daha geniş bir alana yaymak amacıyla Alaşehir'de bir kongre toplanması uygun görülmüştü. Hacim Muhittin (Çarıklı)'in başkanlığında toplanan bu kongre (16-25 Ağustos 1919), Balıkesir'de alınan kararları olduğu gibi benimsemiş bulunuyordu. Öte yandan Batı Anadolu'da bu gelişmeler olurken Doğu Anadolu'da Erzurum Kongresi toplanmı̧̧ ve ülkenin bütün olarak kurtuluşunu esas alan kararlara imza atılmıştı. Kongrede seçilen Temsil Heyeti ile Balıkesir Heyeti Merkeziyesi arasında bağlantı kurulması ülkenin bir bütün olarak kurtarılması gerektiğine olan inancı pekiştirmektedir. Sorun, üçüncü Balıkesir Kongresi (16-22 Eylül 1919)'nin temel gündem maddelerinden biri haline gelmiş ve Mustafa Kemal Paşa tarafından çekilen 13 Eylül 1919 tarihli bir telgrafta Umum Anadolu Kongresi'nin olağanüstü olarak toplanması gereğine işaret olunmuştu (s. 124-125). Sivas'la bağlantı kurulması, yabancıların kongreyle ilgilenmesi, İtilaf devletlerine iki muhtıra

${ }^{4}$ Türk Devrim Tarihi, Ankara, 1991, I, 276. 
verilmesi, Ferit Paşa aleyhine harekete geçilmesi, bu üçüncü Balıkesir Kongresinin başarı hanesine yazılacak önemli gelişmeler olarak kaydedilmesi gerekir.

Prof. Turan'ın da vurguladığı gibi Balıkesir Merkez Heyetinin Kongre sonrası önemli bir girişimi de, Kongre kararlarını kamuoyuna duyuracak ve Kuva-yı Milliye bilincini yayacak bir gazetenin çıkarılması olmuştur ${ }^{5}$. Gazete yayın hayatına 16 Ekim 1919'da başlamış ve Balıkesir'in Yunan işgaline uğramasından üç gün öncesine (27 Haziran 1920) kadar yayımını sürdürmüştür. Yukarıda değindiğimiz gibi bu gazete İzmir'e Doğru'dur. Bunun Anzavur ayaklanmasına, İstanbul hükümeti ve basınına karşı yaman bir savaşım verdiğini unutmamak gerekir.

Öte yandan Anzavur ayaklanmasının patlak vermesi ve giderek yayılması Batı Anadolu'da tehlikeli bir durum yaratmış, bu arada Yunan Ordusuna karşı Kuva-yı Milliye önemli başarılar elde etmekten geri kalmamıştı. Biriken sorunların üstesinden gelmek için dördüncü bir kongrenin toplanması (19-21 Kasım 1919), Mustafa Kemal Paşa'nın büyük tepkisine yol açmıştı. Çünkü Batı Anadolu'daki redd-i ilhak heyetleri Sivas Kongresi'nde oluşan Anadolu ve Rumeli Müdafaa-i Hukuk Cemiyetine katılmakta yavaş davranmışlar ve yeni bir kongre yapılması ve buna Bursa çevresinin de katılmasının sağlanması yoluna gitmişlerdi. Mustafa Kemal Paşa, 14 Ekim'de Osman Nuri Beye çektiği telgrafta redd-i ilhak ve benzeri kuruluşların, Sivas Kongresinde tek bir çatı altında birleştiğini vurgulayarak hepsinin temsilcilerinin Heyet-i Temsiliye olduğunu dile getirdi. Bu telgraf, Balıkesir örgütünde büyük bir duraksamaya yol açmakla birlikte Kongre çalışmalarını sürdürdü. Sivas'a bir delege gönderilmesi konusu tartışıldı, fakat kesin bir sonuca varılamadı. Sonunda Hacim Muhittin'in imzasinı taşıyan bir mektup, Ethem Bey aracılı̆̆ıyla Sivas'a gönderildi. Mektubun içeriğinden (s. 160) Sivas'a bağlı olmanın bölge çıkarlarına aykırı görüldüğü dile getiriliyordu.

Balıkesir Heyeti Merkeziyesi ile Heyeti Temsiliye arasındaki ilişkilerin giderek yakınlaşmaya doğru gittiğine şüphe yoktur. Kongrenin önemli çalışmalarından biri olan Akbaş cephaneliği baskını, Mustafa Kemal'in takdirini kazanmıștır. Akbaș cephaneliğinden kaçırılan silahlardan ne yazık ki yeterince yararlanılamamış ve Anzavur bu silahları imha ederek ülkeye en büyük hıyaneti yapmaktan çekinmemiştir.

Ankara ile Balıkesir arasındaki yakınlaşmaya karşın Heyeti Merkeziye yeni bir kongrenin, yani beşinci Balıkesir Kongresinin toplanması yeniden gündeme geldi (10-22 Mart 1920). Bu kongreye Karesi ve Saruhan livalarıyla Bursa vilayeti ve Bilecik sancağı merkezi liva ve bütün kaza ve nahiye temsilcileri katıldılar. Beşinci Kongreye bu delegelerin katılması, bu toplantının kapsamını açıkça ortaya koymaktadır. Kongre toplantılarının

\footnotetext{
${ }^{5}$ Türk Devrim Tarihi, I, 289.
} 
sürdüğü sırada İstanbul resmen ișgal edildi. Kongre (İzmir Şimal Mıntakası Kongresi) 22 Mart Pazartesi günü son toplantısını "yakında bütün badirelerden" kurtulacağına olan inancını dile getirerek kapand. Balıkesir'de diğer önemli bir gelişme de Tümen komutanı Kâzım (Özalp)'ın 20 Martta güvenliği sağlamak için oldukça sert içerikli bir bildiri yayınlamış olmasidir.

30 Haziran'da Balıkesir'in işgal edilmesi, Milli Mücadele tarihinde önemli bir dönüm noktasıdır. Kentin işgal edilmesi Heyet-i Merkeziyenin umudunu kırmadı. Balıkesir ve Batı Anadolu'da Kuva-yı Milliyenin öncülüğünü yapan Mustafa Necati, Vasıf, Hacim Muhittin, Mahmut Celal, Hayrettin, Abdülgafur Efendi ve daha nice soylu yurtseverler ülkenin kurtarılmasında ve yeni bir devletin temellerinin atılmasında üzerlerine düşen görevi başarıyla yerine getirdiler. Kitabın ekleri, şimdiye değin yayınlanmamış pek çok özgün belgeyi kapsamaktadır. Bu araştırma Milli Mücadele tarihinin başlangıcını ve en bunalımlı bir dönemini aydınlatmakta ve bu bağlamda son yıllarda başlayan araştırmalara önemli bir katkıda bulunmaktadır. Yalnız bir haritanın eksikliğinin duyulduğunu da özellikle belirtmek gerekir. 